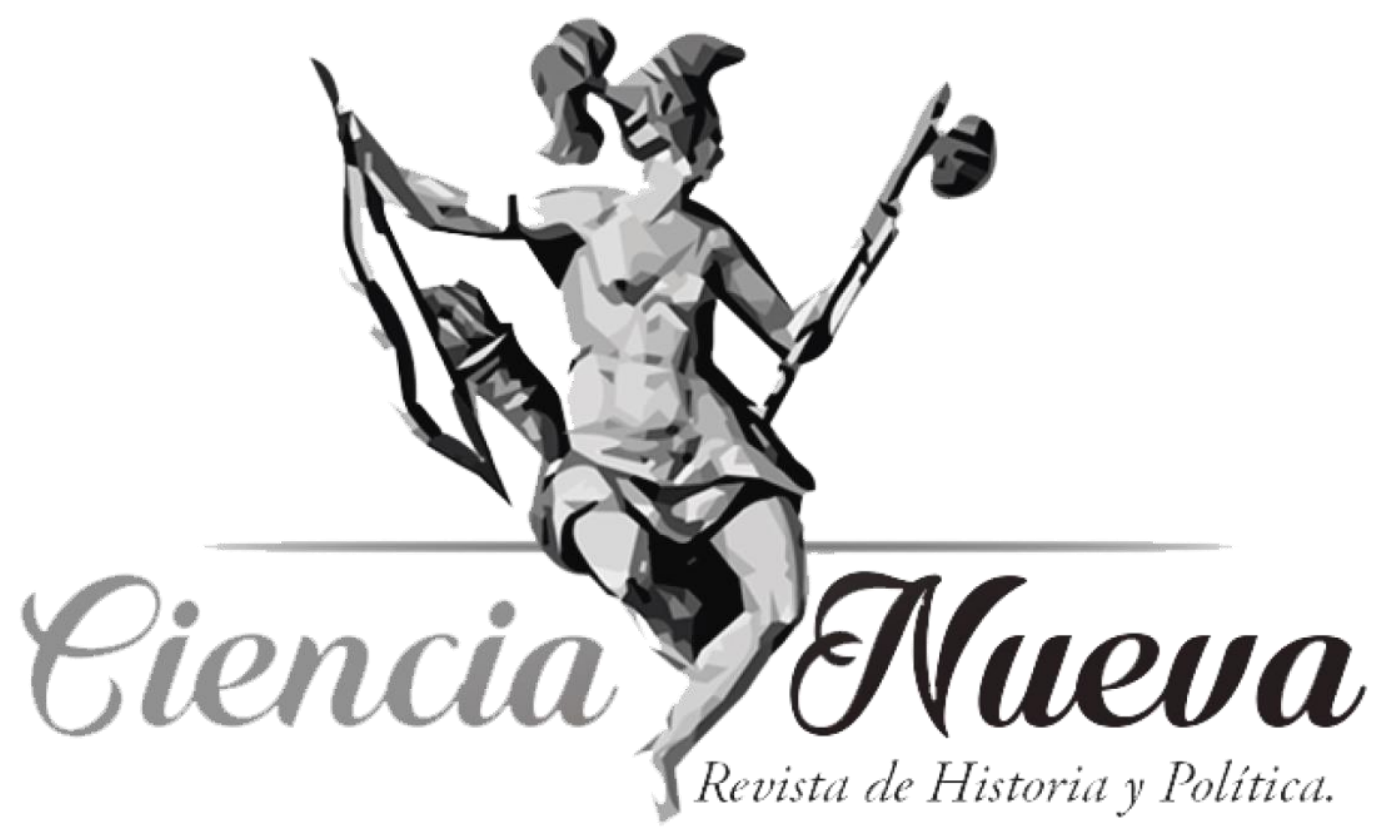

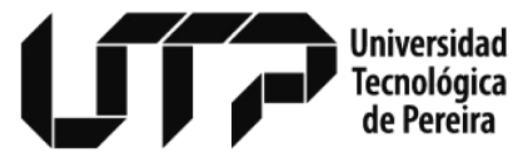

Maestría en Historia

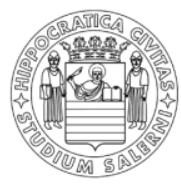

UNIVERSITÀ DEGLI STUDI DI SALERNO

Maestría en Ciencia Política

DOSSIER ESPECIAL "PERSPECTIVAS SOBRE LOS CIEN AÑOS DE LA REVOLUCIÓN RUSA"

\title{
EL CINE SOVIÉTICO A PROPÓSITO DE LOS CIEN AÑOS DE LA REVOLUCIÓN RUSA
}

THE SOVIET CINEMA WITH REGARD TO THE CENTENARY OF THE RUSSIAN REVOLUTION

Natalia Agudelo Castañeda pp. $78-86$

Vol. 2 Núm. 3, Diciembre de 2018

Pereira, Colombia 


\title{
EL CINE SOVIÉTICO A PROPÓSITO DE LOS CIEN AÑOS DE LA REVOLUCIÓN RUSA* THE SOVIET CINEMA WITH REGARD TO THE CENTENARY OF THE RUSSIAN REVOLUTION
}

\author{
Natalia Agudelo Castañeda** \\ nataagudelo@utp.edu.co
}

ORCID: http://orcid.org/0000-0003-4305-5426

\begin{tabular}{rll}
\hline Recibido: & 04 de mayo de 2018 \\
Revisado: & 13 de agosto de 2018 \\
Aceptado: & 19 de noviembre de 2018 \\
Publicado: & 05 de diciembre de 2018 \\
\hline
\end{tabular}

\section{Resumen}

Este artículo realiza un breve recuento sobre los primeros años del cine ruso y su vinculación orgánica a los hechos que han sido denominados "Revolución rusa", acaecidos en el año de 1917. Al respecto, vale la pena aclarar que las producciones cinematográficas que serán abordadas en este documento fueron producidas en el último periodo del zarismo en Rusia hasta poco después de la Revolución de Octubre en 1917. En este sentido, se expondrán pequeñas reseñas y marcos contextuales que logren ubicar especialmente la temática de las películas y la intención narrativa de sus directores, las cuales marcaron cercanías y distancias ideológicas con la revolución, como también nuevos tiempos en la narrativa cinematográfica y sus aportes, de cara al escenario mundial.

Palabras clave: Cine, cine ruso, centenario de la Revolución Rusa.

\begin{abstract}
This article intends to provide a description of the early years of Russian cinema and its connection with the events known as "Russian Revolution", occurred in 1917. We will analyze some cinematographic productions that were made in the last stage of the Russian monarchy, until shortly after the October Revolution. In this sense, we expose small reviews and contextual frameworks that manage especially to locate the theme of the films and the narrative intentions of the directors, in which productions they suggested a sort of ideological proximities and distances with the revolution, even new times in the film narrative and its contributions towards the global stage.
\end{abstract}

Keywords: Cinema, russian cinema, centenary of Russian revolution.

\footnotetext{
* El presente artículo respeta las directrices y normas dispuestas en la Declaración de Ética de Publicación de Ciencia Nueva, Revista de Historia y Política. Esta declaración puede consultarse en la página web de la revista: revistas.utp.edu.co/index.php/historia. Este artículo corresponde a una versión mejorada de la ponencia "Rusia: El cine y la revolución", presentada por la autora en el Coloquio "Perspectivas sobre los cien años de la Revolución rusa" realizado por la Maestría en Historia de la Universidad Tecnológica de Pereira el 21 de noviembre de 2017.

** Licenciada en Comunicación e Informática Educativa y estudiante de la Maestría en Historia de la Universidad Tecnológica de Pereira. Integrante del Grupo de Investigación "Políticas, Sociabilidades y Representaciones Histórico-Educativas (PSORHE)". Asesora pedagógica del Centro de Innovación Educativa de la Universidad Católica de Pereira.
} 


\section{Introducción}

El surgimiento del cine se les atribuye a los hermanos Lumière, cuando hicieron la proyección con el cinematógrafo de una serie de imágenes en movimiento en el año de 1895 en París. Para 1896, Georges Méliès demostró que este instrumento servía no sólo para reproducir la realidad, sino también para falsearla, con lo que surgió el cine de una sola bobina. Siete años después, con estos dos elementos - la ficción y la herramienta que podía reproducir imágenes en movimiento-, en el estudio de Edison en Estados Unidos, Edwin S. Porter unió el estilo documental de los Lumière y las fantasías de Méliès, para dar origen al cine de ficción. Produjo la primera película norteamericana de interés, "Asalto y robo de un tren" en 1903, con una duración de 8 minutos. Incluía innovaciones como el montaje de escenas filmadas en distintos momentos y locaciones, componiendo una unidad narrativa.

Sobre el cine ruso, se debe resaltar la fuerte influencia que tuvo en el desarrollo del montaje artístico, del rol de los actores, del uso de las gentes del común en las obras donde se requería un volumen exagerado de personas, etc., como también en el ejercicio de comprensión sobre el uso de la imagen para evocar la unidad de un ideal - en este caso del comunismo, y en particular, de la Revolución-, lo que incluso generó una relación fuerte del cine con la iconografía revolucionaria, específicamente con lo que fuera Lenin, el "Octubre rojo", las masas, la fábrica, el obrero y la liberación de los patronos, asuntos que estaban ligados con la instauración de un nuevo sistema político, cultural, social y económico luego de la caída del zarismo en Rusia. A ello se le sumaba el alto porcentaje de analfabetismo de la población, aspecto que el cine pudo doblegar, pues no era necesario un esfuerzo intelectual importante para descifrar las imágenes que se presentaban, ya que eran cercanas a sus contextos.

\section{Inicio del Cine Ruso}

El cine en Rusia hizo presencia desde el siglo XIX con los hermanos Lumière quienes llevaron el film que daba cuenta de la coronación del Zar Nicolás II. Por cuenta de ellos se abrieron las primeras salas de exhibición en Rusia en el año de 1908: Pathé y Gaumont. En 1912 se inauguraron los estudios Jadzhónkov, donde se produjo "Oborona Sevastopolya” (La defensa de Sebastopol) dirigida por Iván Mozhujin, conocida como la primera película en la historia rodada con dos cámaras, que narra la batalla más importante de la Guerra de Crimea. Posteriormente, el cine ruso estuvo configurado por el género literario en el que se iban desarrollando producciones que tenían como centro de atención la adaptación de las obras de Gógol, Tolstói y Dostoyevski. Durante este mismo periodo, se destaca la producción de Geo Bauer, quien era conocido también como el mejor cineasta de la época, y quien logró dejar sentado un precedente importante para el devenir del cine ruso. Entre sus obras más importantes se destaca "Una vida por otra". 


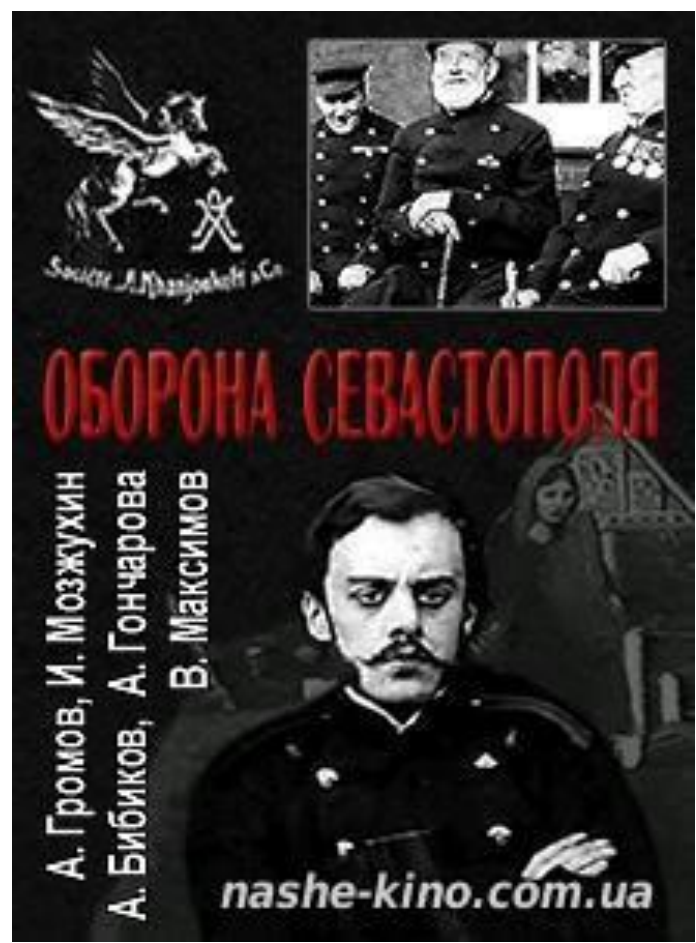

Fotografía 1: Póster de Oborona Sevastopolya.

Luego de la Revolución de febrero de 1917 nació propiamente el cine ruso, cuando Lenin firmó el decreto de la nacionalización del antiguo cine zarista. Sin embargo, sus inicios tropezaron con algunas dificultades propias de la Guerra Civil Rusa (1918-1921), y de las acciones del Ejército Blanco de tendencia pro-zarista que luego de la Revolución de octubre combatió contra el Ejército Rojo. Esta guardia blanca fue financiada por otros países como Japón, Gran Bretaña, Canadá, Francia y Estados Unidos, aspecto que les permitía hacer propaganda contra los esfuerzos bolcheviques. A lo anterior se le sumaban los aprietos que le generaban estos combates a los realizadores cinematográficos $-\mathrm{y}$ a la población en general-, sin electricidad, película, e incluso sin alimentación ${ }^{1}$. En medio de esta situación, la poca producción cinematográfica estuvo en manos de Kuleshov con films como "El plan del Ingeniero Prait" (1917), "No nacido para el dinero" (1919), y "La Señorita y el Pino" (1919).

En 1919, el Gobierno revolucionario ruso nacionalizó la industria cinematográfica y creó una escuela destinada a formar técnicos y artistas. En los años veinte, el joven cine soviético alcanzó extraordinarios éxitos y produjo una serie de obras maestras que hasta ahora son estudiadas en las escuelas de cine de todo el mundo. En 1922, cuando la paz fue restablecida, Vladímir Lenin pronunciaba esta frase al poco tiempo de la victoria de la revolución comunista en Rusia: "De todas las artes, el cine es para nosotros la más importante". Sabía de lo que hablaba: en un país con un $80 \%$ de analfabetismo, la radio y el cine se convertían en la mejor forma de trasmisión de la ideología del nuevo régimen a las masas. A lo largo de ese año se reabrieron los estudios, se reagrupaban los técnicos y los artistas, y la primera y gran producción de este esfuerzo fue "Aelita" (1924) bajo la dirección

\footnotetext{
${ }^{1}$ Georges Sadoul, La historia del Cine Mundial desde los orígenes (México: Siglo XXI editores, 2004$), 164$.
} 
de Protazánov con un estilo constructivista ${ }^{2}$. Este filme hace parte de la producción de cine mudo, y vale la pena señalar que es una adaptación del género de ficción de Alekséi Tolstói -pariente lejano de León Tolstoi-. Esta película narra un viaje de un joven a Marte, donde participa de un levantamiento contra el rey, ayudado por la reina Aelita. La línea argumental representa de manera clara un sentimiento de la época y, en especial, recuerda el alzamiento contra el zarismo en Rusia, además del constante juego simbólico comunista.

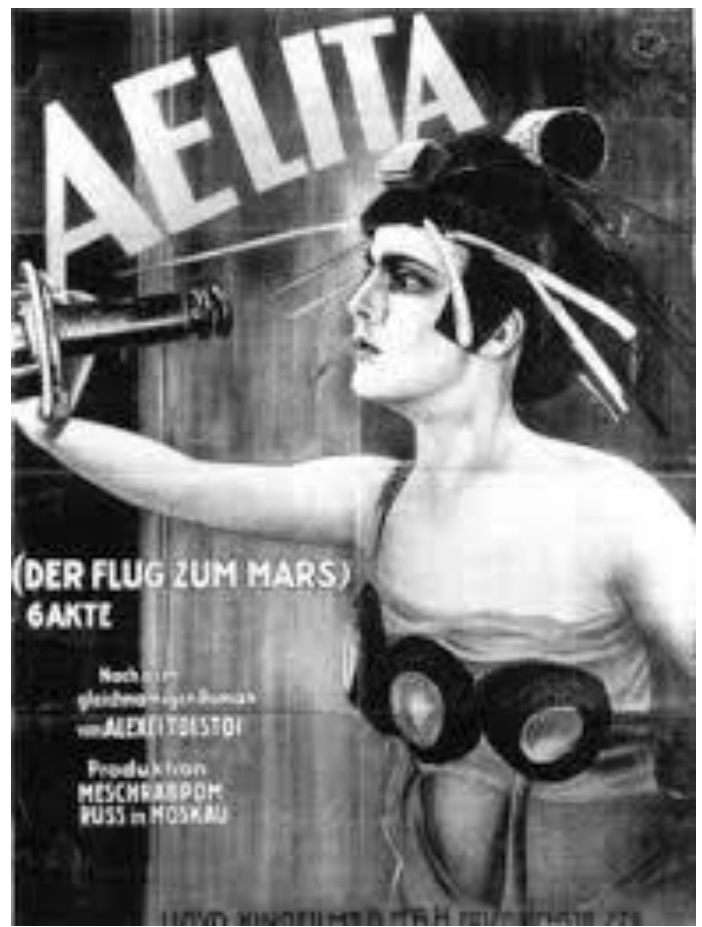

Fotografía 2: Póster de Aelita.

\section{Ahora bien, los nombres de Serguéi Eizenshtéin ${ }^{3}$, Lev Kuleshov ${ }^{4}$, Vsévolod Pudovkin y Dziga Vértov, son internacionalmente conocidos por su producción y su aporte en distintos}

\footnotetext{
${ }^{2}$ El cine constructivista comenzó en la Unión Soviética en la década de 1920. Un grupo de escritores de vanguardia, fotógrafos, diseñadores y críticos soviéticos formaron el Frente de Izquierda de las Artes (LEF), y produjeron la revista "LEF", que se desarrolló desde 1923 hasta 1925, y más tarde como "Novy Lef" entre 1927 y 1929. El objetivo de la revista, como está escrito en uno de sus primeros números, era "re-examinar la ideología y las prácticas del llamado arte izquierdista, y abandonar el individualismo para aumentar el valor del arte para desarrollar el comunismo". Para ellos, el cine era más que una narrativa visual, y podía servir a un propósito. Ellos se dedicaron a la defensa de un medio cinematográfico vanguardista. «Dziga Vertov y cine constructivista», Lomography Magazine, acceso 14 de mayo de 2018, https://www.lomography.com/magazine/241240-dziga-vertov-y-cine-constructivista.

${ }^{3}$ Sergei Mijailovich Eisenstein nació en Riga, capital de la actual Letonia y por aquel entonces ciudad del Imperio Ruso, el 22 de enero de 1898. Hijo de padre judío y de madre eslava, desde muy pequeño destacó por su facilidad y precisión por el dibujo, don que lo llevó en 1914 a ingresar en la Escuela de Arquitectura de San Petersburgo. En ella permaneció tres años, ya que, en 1917, año de la Revolución de Octubre, el futuro arquitecto dio un giro a su orientado porvenir. «Sergei Eisenstein, el descubridor del cine como espectáculo de masas», El País, acceso 14 de mayo de 2018, https://elpais.com/cultura/2018/01/22/actualidad/1516575680_487434.html

${ }^{4}$ Lev Vladímirovich Kuleshov fue uno de los pioneros del cine soviético. Cineasta y teórico famoso por sus experimentos en torno al montaje del cine, Kuleshov aportó experiencias y conocimiento en torno al lenguaje cinematográfico, estuvo encargado de un taller de montaje poco después de la revolución de 1917 y los cineastas
} 
aspectos como montaje, dirección, adaptación, guión, etc. Vértov se destacó por revolucionar el género documental con su innovador filme "El hombre con la cámara" (1929); Lev Kuleshov fue famoso por elaborar nuevas técnicas de montaje, y su discípulo, Vsévolod Pudovkin, fue reconocido por su poderoso drama "La madre", adaptación de la novela de Maksim Gorki rodada en 1926.

Sin embargo, al hablar de cine ruso inevitablemente viene a la mente el nombre de Serguéi Eizenshtéin, quien escaló a la fama en 1925 con el rodaje de "El acorazado Potemkin", considerada una de las películas más importantes de la historia del cine mundial. Este filme introdujo un nuevo lenguaje visual y un método de narración cinematográfica revolucionario para aquellos años. La innovadora y atrevida técnica de montaje inventada por Eizenshtéin sirvió de inspiración para el desarrollo posterior del cine $\mathrm{s}^{5}$.

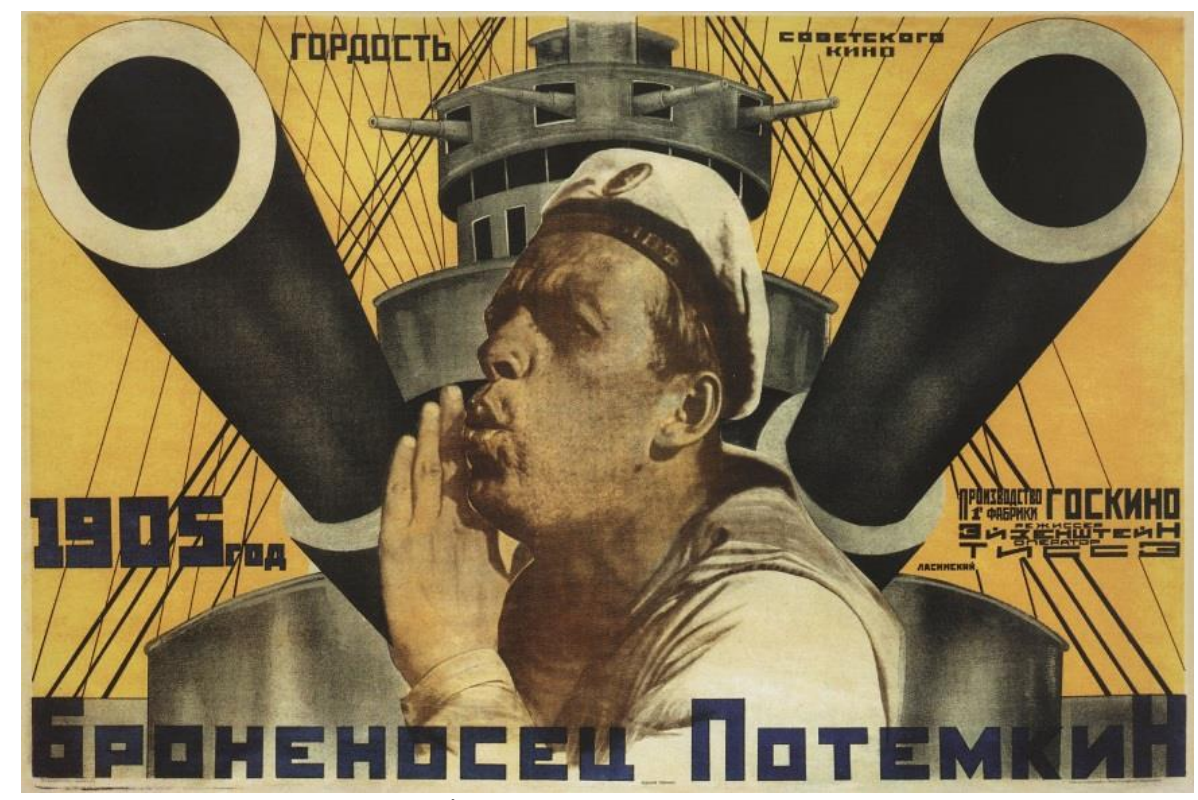

Fotografía 3: El Acorazado de Potemkin.

Durante la década de los años veinte creció la cantidad de estudios cinematográficos en la URSS, y aparecieron empresas dedicadas al cine en la mayoría de las repúblicas del enorme país. Georgia, Kazajistán, Armenia, Ucrania y otras repúblicas soviéticas comenzaron a producir cintas en su territorio; pero los principales productores de cine fueron los estudios de Mosfilm (en Moscú) y Lenfilm (en Leningrado, actual San Petersburgo).

\section{El héroe en el Cine Ruso}

Además de ser una forma de ocio, el cine evidentemente también es un discurso que comunica mensajes a gran escala, en términos de la cantidad de personas a las que puede llegar. En este sentido, las producciones que se exponen a continuación se abordaron no sólo

\footnotetext{
Vsevolod Illarianovich Pudovkin y Sergei Eisenstein fueron sus alumnos.1 En 1922, Pudovkin describió un supuesto experimento que realizó junto con Lev Kuleshov en el cual se intenta explicar lo que llamó "el efecto Kuleshov". El experimento, según lo describe Pudovkin, consistió en la selección de primeros planos del rostro neutral del conocido actor Iván Mozzhujin unidos a fragmentos de otras películas, elegidas ante la ausencia de negativos nuevos para manipular.

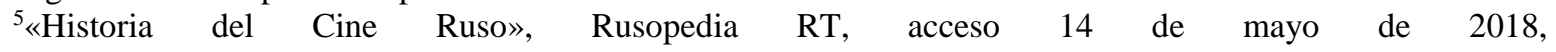
http://rusopedia.rt.com/cultura/cine/issue_109.html
} 
por su carácter histórico, sino por tener también un alto contenido ideológico. Cabe aún señalar que Lenin como héroe y la Revolución de octubre como hito histórico, son dos temas recurrentes en el cine soviético.

De esta manera, encontramos en la obra de Dziga Vértov varias obras importantes en las que se destaca la vida y obra de Lenin, así como la revolución per se. Dentro de los títulos más sonados se encuentran: "Historia de un bocado de pan, un año después de la muerte de Lenin, ¡Soviet en Marcha!" (1926), "La sexta parte del mundo" (1926), "El hombre de la Cámara" (1929), y "Sinfonía del Donetz" (1931). Vértov realizó su obra maestra en los comienzos del cine hablado con "Tres cantos sobre Lenin" (1934), que versa sobre tres canciones populares inspiradas por Lenin. En términos generales, las películas de Vértov mostraban un panorama de Rusia a comienzos de los años treinta en diferentes regiones europeas y asiáticas.

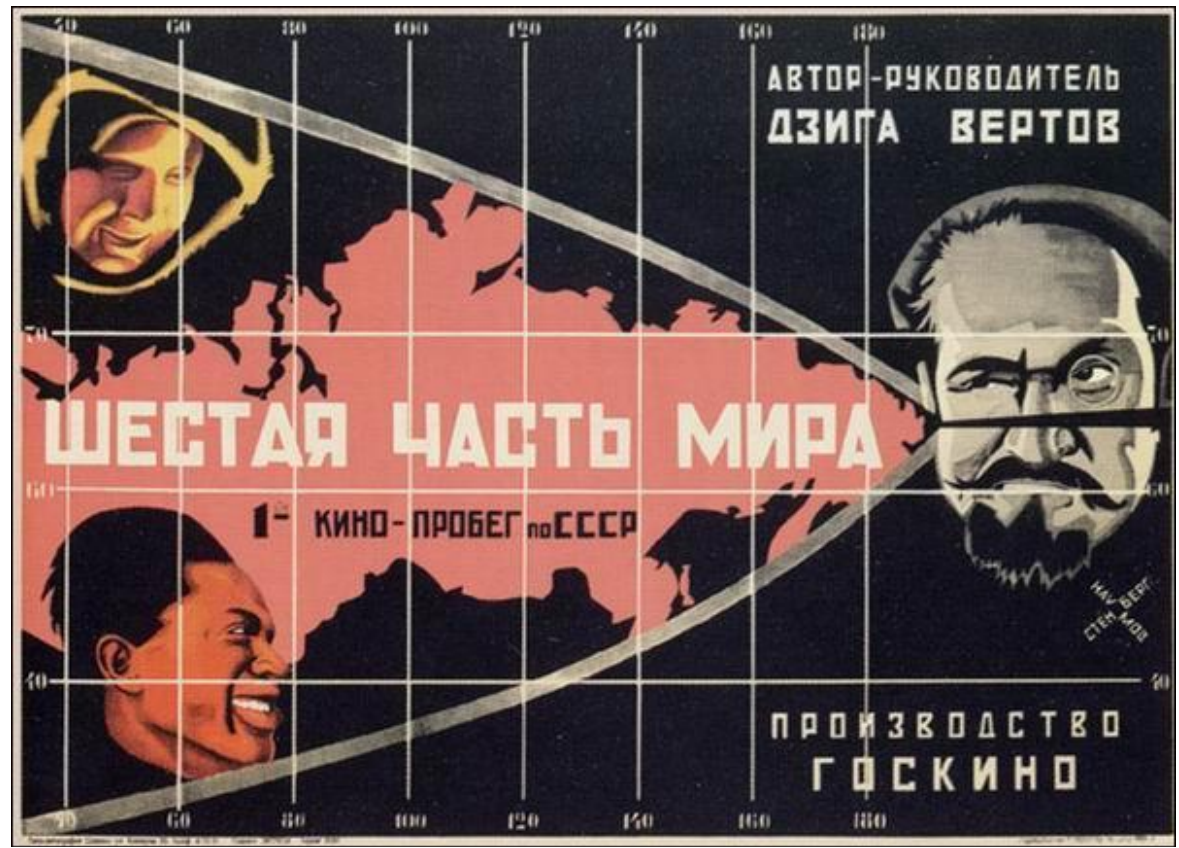

Fotografía 4: Póster de "La sexta parte del mundo" de Dziga Vértov.

La filmografía de Eizenshtéin responde con mayor fuerza al tópico del héroe y a la Revolución rusa. Encontramos, por ejemplo, "La Huelga" (1925), una película cuya idea reside en una obra del Teatro de la Cultura Proletaria, el cual estaba en cabeza de Valeri Pletnev, quien encargó a Eizenshtéin la realización de una serie de películas que llevarían por título "Hacia la dictadura (del proletariado)". El objetivo de estas películas era el de contar la historia de la Revolución rusa desde 1880 hasta 1917, y como no podía ser de otra manera, se centrarían en diversos aspectos de las luchas obreras ${ }^{6}$.

En este sentido, la línea argumental de "La Huelga" gira alrededor de una trama que se desenvuelve en la Rusia zarista. Allí, los obreros de una empresa están cada vez más descontentos con sus condiciones de trabajo y con el trato recibido por parte de sus superiores. Con un ambiente cargado de tensión cada día más fuerte, el director de la empresa

${ }^{6} «$ La Huelga, Sergei M. Eisenstein, 1924», Cine y trabajo, acceso 15 de mayo de 2018, https:/cineytrabajo.wordpress.com/2011/11/13/la-huelga-sergei-m-eisenstein-1924/ 
comunica sus sospechas de un posible motín de los obreros contra los altos funcionarios políticos, y éstos envían a sus informadores. Aunque las nubes de tormenta ya estaban flotando en el ambiente, es cuando un compañero, un obrero, se suicida al ser acusado injustamente de robo, cuando estalla todo y se produce la huelga. Las fuerzas policiales, apoyando a los dueños de las empresas y los accionistas, tomarán cartas en el asunto ${ }^{7}$.

"Octubre" (1928) es otro filme que vale la pena destacar de la obra de Eizenshtéin, que narra los detalles del declive del zarismo, como también de los distintos conflictos en Petrogrado. En esta película en particular, se muestra la grandeza de la figura de Vladímir Ilich Uliánov, o Lenin. Al respecto de su producción, es menester mencionar que fue un encargo de Joseph Stalin para conmemorar el undécimo aniversario de la Revolución, por lo que esta película tiene un valor importante en términos de la representación de los hechos narrados, puesto que hubo una trascendencia a la recreación en la que se teje una línea muy delgada entre los hechos ficcionales y lo real.

Estas producciones dan cuenta no sólo de la producción del cine ruso, sino del cine político que nació con la Revolución rusa de 1917, y que configuró un repertorio discursivo que logró mantener el vínculo militante entre "la masa" y el imaginario revolucionario comunista. En esta relación no hubo contradicción alrededor del poder de la imagen y de lo que ésta podía evocar o movilizar, pues, en palabras de Peter Burke en su libro "Visto y No Visto”, las imágenes son el único testimonio existente de las prácticas sociales, como en este caso la Revolución ${ }^{8}$.

\section{Otras narrativas del cine ruso.}

En el devenir del cine ruso surgieron también otro tipo de tendencias en cabeza de grupos de vanguardia que fundaron algunos jóvenes con apoyo del gobierno, tales como el Laboratorio Experimental Kuleshov y la Fábrica del Actor Excéntrico (FECKS) de Kózintsev, Trauberg, Yutkévitch y Gerasimov9.

En el Laboratorio Experimental Kuleshov se llevaron a cabo los "films sin película" mediante fotos fijas, poniendo de relieve el poder creador del montaje con un famoso experimento en el que se conseguía infundir diferente fuerza emocional a un único primer plano inexpresivo de un actor, según el contenido de los planos que le yuxtaponía: un cadáver, una mujer, un plato de sopa, un niño.

Luego, la Fábrica del Actor Excéntrico (FECKS) se consolidó como una de las escuelas que le dieron un viraje a la perspectiva de producción. Esta tendencia se basaba en las teorías de Kuleshov y de Meyerhold para instruir a los actores. Estaban influenciados por la comedia del arte italiano, burlesca y pantomímica, y cuidaban el gesto ante la cámara, para darle un valor satírico. Aunque con objetivos muy distintos, la FEKS ofrecía similitudes con el expresionismo en el entendimiento de la interpretación ${ }^{10}$. Dicha escuela inició después de la Revolución de Octubre y de la publicación del Manifiesto del Excentricismo ${ }^{11}$ en el que se plantea una separación definitiva del arte burgués.

\footnotetext{
${ }^{7}$ Sinopsis tomada de Cine y trabajo.

${ }^{8}$ Peter Burke, Visto y no visto. El uso de la imagen como documento histórico, trad. por Teófilo de Lozoya (Barcelona: Crítica, 2005).

${ }^{9}$ Sadoul, La historia del Cine..., 165.

10 «La Fábrica del Actor Excéntrico», La escuela Rusa del Montaje, acceso 15 de mayo de 2018, http://escuelarusamontaje.blogspot.com.co/2011/10/la-fabrica-del-actor-excentrico.html

${ }^{11}$ Escrito desarrollado por la FECKS en el año de 1922.
} 
Dentro de estas nuevas tendencias y/o géneros del cine ruso se destacan los primeros films editados, en los que Esther Shub ${ }^{12}$, con grandes filmotecas de antigüedades zaristas y revolucionarias, realizó "La Rusia de Nicolás II y de Tolstoi", "La caída de los Romanov", "La gran vía", "Hoy", "El país de los Soviets", entre otros. A este material se le ha considerado entre artístico e histórico, pues la mayoría de estas creaciones fueron realizadas con documentos auténticos, registrados por operadores del zarismo, configurándose a partir de 1940 como "la historia sobre el vivo".

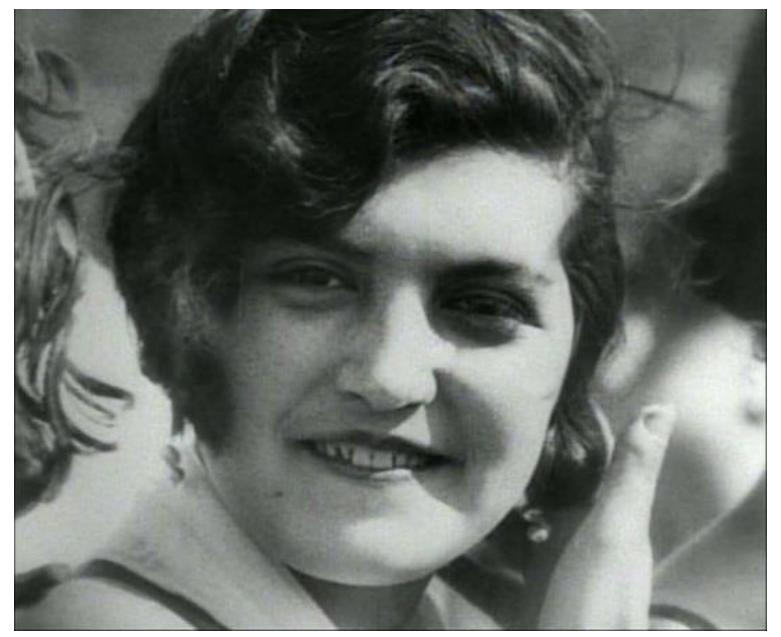

Fotografía 5: Esther Shub.

Para concluir, sobra decir que dentro de los innumerables aportes de los rusos al cine, se encuentran las técnicas de montaje, el realismo, el constructivismo, técnicas en las que se destaca el efecto Kuleshov, que ha sido catalogado como una de las técnicas fílmicas más interesantes y escalofriantes alguna vez divisadas, no sólo por su sencillez, sino también por su brutal efectividad al punto de, literalmente, ser capaz de manipular la percepción del público sobre un personaje en unos pocos segundos, aspecto que se configuró como un hito importante para el devenir del cine en años posteriores.

\footnotetext{
${ }^{12}$ Esther Il'inichna Shub, fue una pionera del cine soviético y editora de documentales. Fue una de las pocas mujeres que tuvieron un papel importante como cineastas en la Unión Soviética. Sus películas más conocidas son Padenie dinastii Romanovykh (1927), Velikiy put (1927) y Rossiya Nikolaya II i Lev Tolstoy (1928).
} 


\section{Bibliografía}

\section{Libros}

Burke, Peter. Visto y no visto. El uso de la imagen como documento histórico. Trad. por Teófilo de Lozoya. Barcelona: Crítica, 2005.

Sadoul, Georges, La historia del cine mundial desde los orígenes. México: Siglo XXI Editores, 2004.

\section{Sitios Web}

«Historia del Cine Ruso». Rusopedia RT. Acceso el 14 de mayo de 2018. http://rusopedia.rt.com/cultura/cine/issue_109.html

«La Fábrica del Actor Excéntrico». La escuela Rusa del Montaje. Acceso 15 de mayo de 2018. http://escuelarusamontaje.blogspot.com.co/2011/10/la-fabrica-del-actorexcentrico.html

«La Huelga, Sergei M. Eisenstein, 1924». Cine y trabajo. Acceso 15 de mayo de 2018. https://cineytrabajo.wordpress.com/2011/11/13/la-huelga-sergei-m-eisenstein-1924/

«Sergei Eisenstein, el descubridor del cine como espectáculo de masas». El País. Acceso 14 $\begin{array}{llll}\text { de mayo } & \text { de } & \end{array}$ https://elpais.com/cultura/2018/01/22/actualidad/1516575680_487434.html 